\title{
DESIGN AND ANALYSIS OF A TURBOPUMP FOR A CONCEPTUAL EXPANDER CYCLE UPPER-STAGE ENGINE
}

\section{FEDMS2006-98101}

\author{
Daniel J. Dorney, ER42, NASA Marshall Space Flight Center, AL 35812 \\ Jeffry Rothermel, ER42, NASA Marshall Space Flight Center, AL 35812 \\ Lisa W. Griffin, ER42, NASA Marshall Space Flight Center, AL 35812 \\ Randall J. Thornton, ER31, NASA Marshall Space Flight Center, AL 35812 \\ John C. Forbes, ER34, NASA Marshall Space Flight Center, AL 35812 \\ Stephen E. Skelley, ER42, NASA Marshall Space Flight Center, AL 35812
}

Frank W. Huber, Riverbend Design Services, Inc., Palm Beach Gardens, FL 33418

\begin{abstract}
As part of the development of technologies for rocket engines that will power spacecraft to the Moon and Mars, a program was initiated to develop a conceptual upper stage engine with wide flow range capability. The resulting expander cycle engine design employs a radial turbine to allow higher pump speeds and efficiencies. In this paper, the design and analysis of the pump section of the engine are discussed. Onedimensional meanline analyses and three-dimensional unsteady computational fluid dynamics simulations were performed for the pump stage. Configurations with both vaneless and vaned diffusers were investigated. Both the meanline analysis and computational predictions show that the pump will meet the performance objectives. Additional details describing the development of a water flow facility test are also presented.
\end{abstract}

\section{INTRODUCTION}

In recent years, major advancements have been made in the accuracy, applicability, and speed of turbomachinery design and analysis tools. These tools have been successfully applied in a parametric fashion to developing design solutions for gas generator and staged combustion turbomachinery. In the current work, design solutions to overcome turbomachinery challenges encountered in expander cycle engines have been investigated, with the goals of improving turbine and pump efficiency within weight and size constraints developed by the engine system. A representative expander cycle was chosen, and a conceptual upper-stage engine developed. The engine system was modeled using P-STAR, a conceptual engine system sizing, thermal, and weight analysis code [1]. The turbopump requirements were derived from the results of the engine system model. A radial turbine design was chosen to allow higher pump speeds. The radial turbine design performed comparably to the axial turbine at the design point, and showed improved off-design performance characteristics. A turbopump with a speed increase over the baseline was developed, increasing predicted turbine and pump efficiency.

The focus of the current paper is on the design and analysis of a scaled water test model of the first stage of the prospective two-stage pump, including inlet guide vanes, impeller, and diffuser. Future papers will provide details on the design of the radial turbine, and the results of water flow tests which will occur during the spring of 2006.

\section{DESIGN}

Basic pump design requirements for the test rig include a flow rate of $977 \mathrm{gpm}$ and an overall head rise of approximately $334 \mathrm{ft}$ at $3600 \mathrm{rpm}$ in water. A throttling requirement down to about $70 \%$ of the pump design flow coefficient has also been imposed.

The Concepts NREC Agile Engineering Design System [2] was used to design the pump flow path. This process began with meanline sizing using the PUMPAL module [2]. The rig 
was configured to test the $7+7$ (i.e., main plus splitter) blade unshrouded impeller with a 15-vane inlet guide vane assembly (the inlet guide vanes being used provide the proper impeller inlet conditions), and either a vaneless diffuser space or a 17vane vane-island type diffuser downstream of the impeller. The meanline flow path (not to scale) is depicted in Fig. 1. The meanline calculations are done independently of the axial length, thus Fig. 1 is representative of only the radial positions. No adjustment is made for axial position of the IGV's in the meanline model.

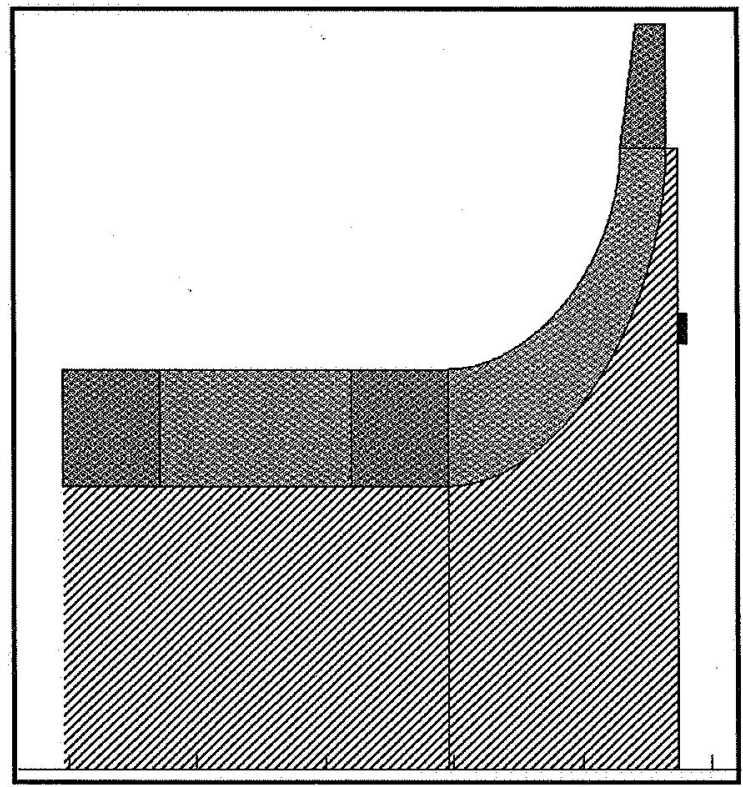

Figure 1. Meanline pump flow path. Green and pink denote inlet guide vanes and main/splitter blades, respectively.

Once the meanline flow path was established, a head-flow performance map (Fig. 2) was created within the PUMPAL module to verify that the operating range would satisfy the stated requirement. The predicted stall line for the pump is depicted as the dashed line along the left edge of the map, and ranges between roughly $55 \%$ and $60 \%$ of the design flow coefficient.

After developing a meanline flow path that satisfied the basic requirements, the three-dimension blade profiles were developed and analyzed with the Concepts NREC CCAD module [2]. CCAD uses the output from the PUMPAL meanline module to develop the blade geometry in an interactive environment. CCAD allows the designer to manipulate blade geometry parameters such as angle distribution, thickness profiles, leading edge profile, etc. A multiple-streamtube calculation (MST), which is a streamline curvature technique that solves a velocity equation along quasiorthogonals, is carried out within the CCAD module, allowing immediate

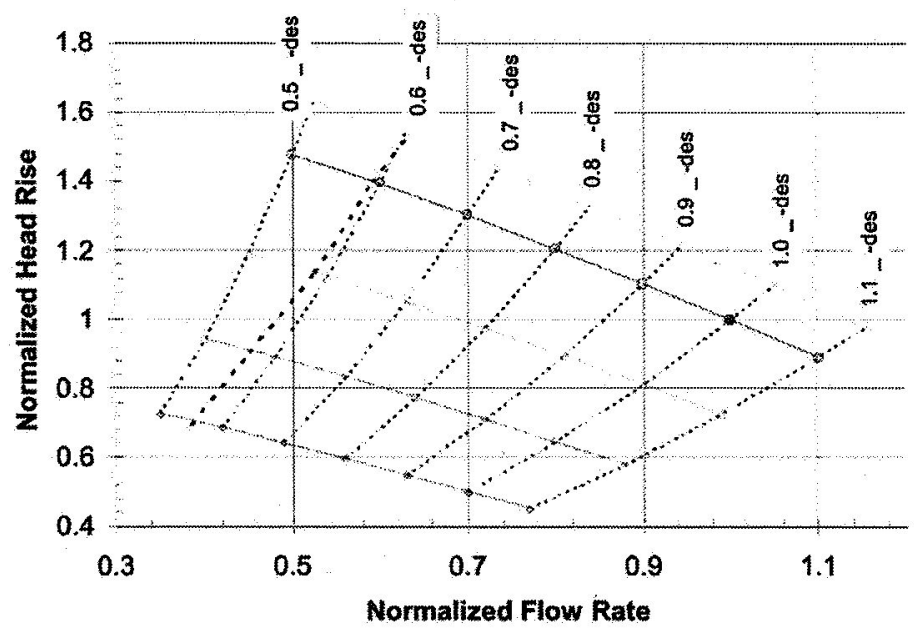

Figure 2. Predicted pump head-flow performance.

evaluation of the effect of geometry changes to blade loading, incidence angles, velocity distributions, etc. During the design process an optimized impeller configuration was eventually achieved by inserting splitter blades in the impeller flow path. A $7+7$ blade configuration was settled on, as it gave the proper blade-to-blade loading characteristics. The leading edge of the splitter blade was positioned to minimize passage blockage, as well as to share the total required loading before the main blade separated. A three dimensional rendering of the geometry is shown in Fig. 3.

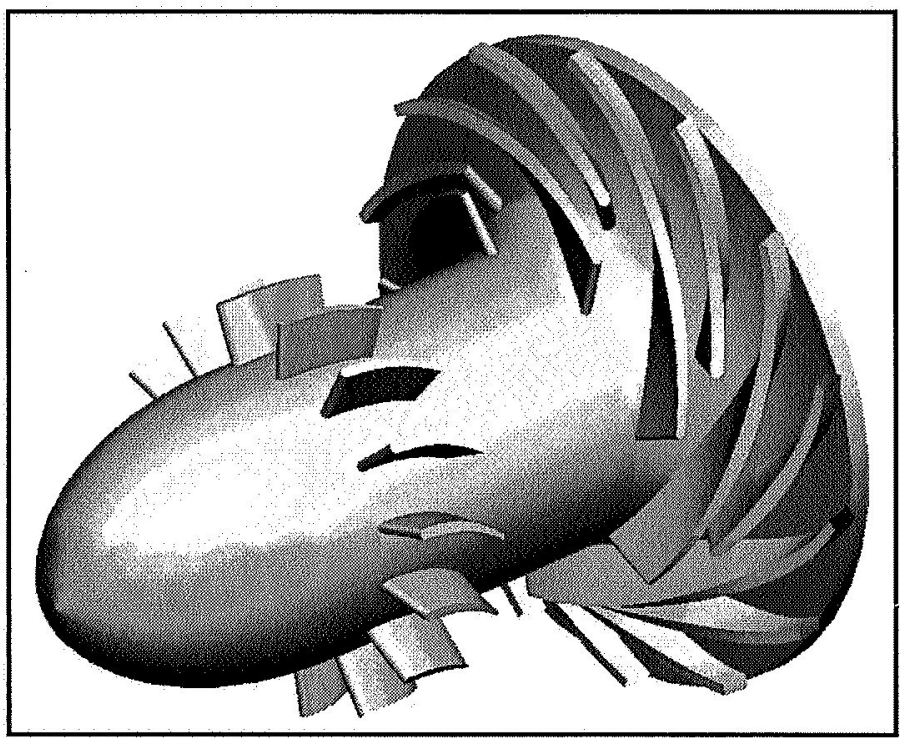

Figure 3. Inlet Guide Vane - Impeller configuration; flow enters from lower left.

Figures 4 and 5 present, respectively, the MST calculation results for streamlines and pressure rise through the first impeller. The predicted streamline curvatures are all smooth, and the pressure rise through the passage is quite even as well. The small shift in the pressure rise profile at approximately 
$30 \%$ of the meridianal passage length is due to the introduction of the splitter blades.

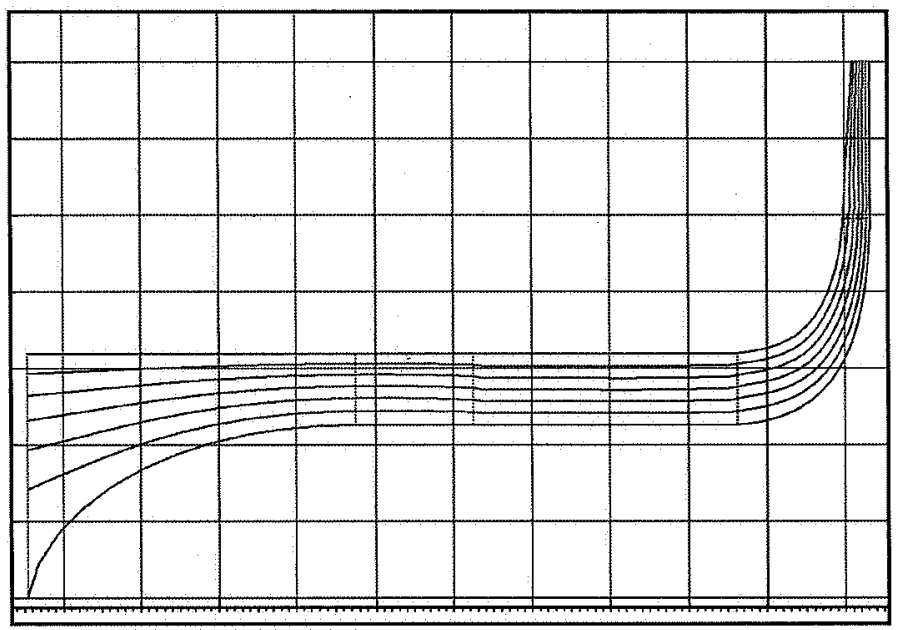

Figure 4. Calculated stream lines from MST analysis.

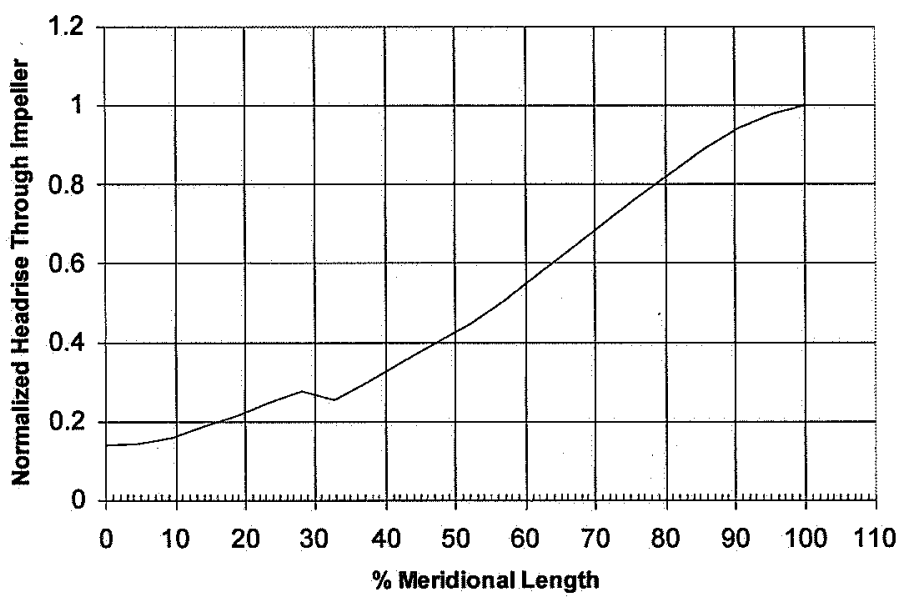

Figure 5. Predicted head rise through impeller from MST analysis.

The flow path was then evaluated with three-dimensional unsteady numerical analysis (described in the next two sections), and a minor adjustment to the impeller leading edge blade angle was made based on the results.

\section{NUMERICAL PROCEDURE}

Turbomachines for propulsion applications operate on many different fluids and under a wide range of flow conditions. The working fluid may be air, liquid or gaseous hydrogen, liquid or gaseous oxygen, kerosene, etc. The flow may be incompressible, such as in the fuel pump in a liquidfueled rocket engine, or supersonic, such as in the turbine that may drive the fuel pump.

Both compressible and incompressible flows are governed by the Navier-Stokes equations. However, in a nearlyincompressible flow there is a great disparity in wave speeds, since the speed of sound approaches infinity for a truly incompressible fluid. A compressible flow solver will encounter numerical "stiffness" (i.e., require small timesteps for computational stability to achieve solution convergence) if applied to a nearly-incompressible flow, and the algorithm will fail. Because of this, it is common practice to use one algorithm for incompressible flows and a different algorithm for compressible flows.

The General Equation Set (GES) method [3] has been developed to handle both compressible and incompressible flows. It can be used to solve the full, unsteady, threedimensional Navier-Stokes equations, and, with the introduction of a single input flag, can reduce to the pseudocompressibility method commonly used to solve incompressible flows. When used in conjunction with a dual time step, it provides time-accurate simulations. In addition, when the Navier-Stokes equations are cast in their general form, without applying the perfect gas relation, they can be solved for any working fluid for which properties are available. The GES technique in conjunction with the equations cast in this general form results in a general flow solver applicable to most conditions encountered in turbomachinery applications. The PHANTOM code, written to solve three-dimensional, unsteady turbomach-inery flows using the GES method, has been used to analyze the present case.

The PHANTOM code structure is based on a wellestablished compressible, 3-D, unsteady turbomachinery flow code [4]. It employs a system of overset $\mathrm{O}$ - and $\mathrm{H}$-grids, with the values on the $\mathrm{O}-\mathrm{H}$ boundaries being updated each time step by bilinear interpolation from the adjacent grid. The inviscid fluxes are third-order spatially accurate and are calculated using Roe's scheme [5]. The viscous fluxes are calculated using second-order accurate central differences, and the code is second-order accurate in time. A modified Baldwin-Lomax turbulence model is used for turbulence closure [6]. Parallel processing capability is available in PHANTOM through use of Message Passing Interface (MPI).

The code contains two options for determining fluid properties. The first option is based on the equations of state, thermodynamic departure functions and corresponding state principles constructed by Oefelein [7]. The second option is based on splines generated from the NIST Tables [8], and is computationally more efficient. The code currently contains fluid property routines (both gaseous and liquid) for water, hydrogen, oxygen, nitrogen, RP-1, methane, carbon monoxide, xenon, hydrazine, monomethylhydrazine, and nitrogen tetroxide. PHANTOM has two-phase flow simulation capability, however the present study assumes single-phase flow.

\section{Computational Grids}


The O-grids are body-fitted to the surfaces of the airfoils and generated using an elliptic equation solution procedure. They are used to properly resolve the viscous flow in the blade passages and to easily apply the algebraic turbulence model. The algebraically generated $\mathrm{H}$-grids are used to discretize the remainder of the flow field. The tip clearance region was explicitly modeled. The complete annulus of the pump was simulated, rather than a periodic sub-set of the full design.

The computational grids move to simulate the motion of the actual geometry (e.g., the rotation of turbomachinery blading).

\section{Boundary Conditions}

For incompressible inlet flow the mass flow, total temperature, and the circumferential and radial flow angles are specified as a function of the radius. The static pressure is extrapolated from the interior of the computational domain.

For incompressible outflow two velocity components, static pressure, and the static temperature are extrapolated from the interior of the computational domain. The exit mass flow is specified.

Periodicity is enforced along the outer boundaries of the $\mathrm{H}$ grids in the circumferential direction.

At solid surfaces the relative velocity is set to zero, the normal derivative of the pressure is set to zero, and the surfaces are assumed to be adiabatic.

A detailed description of the code/algorithm development, as well as its application to several turbine and pump test cases, is presented in Refs. [9-11].

\section{NUMERICAL SIMULATIONS}

The actual pump design is intended for operation with cryogenic fuel and oxidizer, in this case liquid $\mathrm{H}_{2}$ and liquid $\mathrm{O}_{2}$, respectively. The numerical predictions described herein, however, correspond to the version of the pump designed to operate in water.

In an effort to capture accurately the unsteady interactions between bladed components, the entire annulus ( 15 guide vanes and 14 impeller blades) was modeled. The leakage paths behind the impeller were not modeled. The final grid topology was comprised of $91 \mathrm{O}$-grids, $\mathrm{H}$-grids and clearance grids. Based on previous pump simulations, as well as a grid resolution study, a total 4.75 million grid points were used to discretize the pump. Resulting $\mathrm{y}^{+}$values at the hub and nonrotating shroud are $\leq 4$; values at the airfoil are $\sim 1.0$. Thus, resolution near the hub, shroud, and airfoil surfaces is sufficient to capture essential turbulent boundary layer features. The impeller is assumed to be unshrouded, i.e., radially enclosed by a non-rotating casing. The tip clearance region was included in the simulation, and matched that of the water rig. The computational grid is shown in Fig. 6. Simulations were performed on 72-106 processors on an SGI Altix with $1.5 \mathrm{GHz}$ Intel Itanium 2 processors. The simulations required $\sim 1.75$ seconds per iteration and were run for 4 - 11 revolutions of the impeller. The lower limit arises from the practice of initializing some runs from the converged solution for other rotation speeds. Mean calculations are based on time averaging the time-dependent results over one revolution.

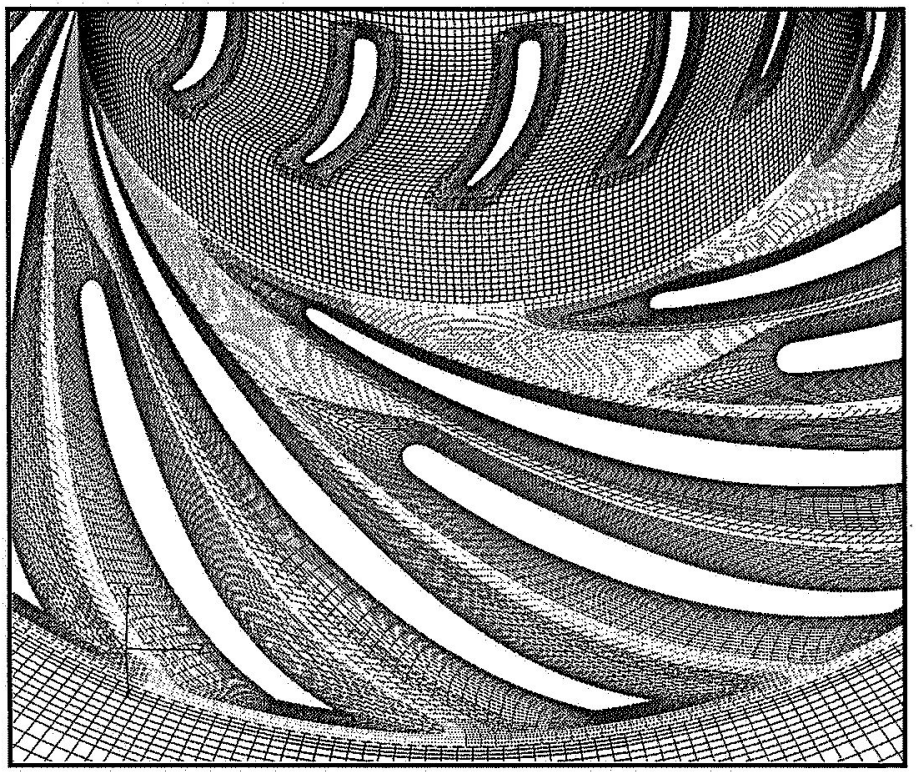

Figure 6. Grid distribution at mid-span depicting inlet guide vanes (near top of figure), impeller main and splitter blades (middle), and vaneless diffuser (bottom). Red denotes $\mathrm{O}-$ grids; other colors denote H-grids.

The laboratory scale model of the pump stage will operate in water, at a temperature of approximately $560 \mathrm{deg}$ Rankine. The impeller will rotate at $3600 \mathrm{rpm}$. Table 1 presents performance parameters at the design flow conditions for the IGV, impeller, and vaneless diffuser combination as predicted by numerical simulation and a meanline analysis. The relatively high hydrodynamic efficiency is a direct result of using a high rotation speed (made possible through the use of a radial turbine), as well as considering only hydrodynamic losses.

Figure 7 illustrates the time-averaged static pressure distribution on the solid surfaces of the pump. The inlet guide vanes are used for giving pre-swirl to the flow entering the impeller, and do not contribute to the overall pressure rise in the pump. The pressure rise in the impeller is nearly linear with meridional distance. The splitter blades achieve the goal of reducing/eliminating separation on the main blades, while not introducing excessive frictional losses.

\begin{tabular}{|l|c|c|}
\hline \multicolumn{1}{|c|}{ Parameter } & Meanline & CFD \\
\hline Tip Speed, $\mathrm{U}_{\mathrm{t}}(\mathrm{ft} / \mathrm{s}(\mathrm{m} / \mathrm{s}))$ & \multicolumn{2}{|c|}{155.8} \\
\hline Volumetric Flow Rate $(\mathrm{gpm})$ & \multicolumn{2}{|c|}{977} \\
\hline
\end{tabular}




\begin{tabular}{|c|c|c|}
\hline $\begin{array}{r}\text { Specific Speed, } N_{S} \\
\left(\mathrm{rpm}^{\circ} \mathrm{gpm}^{1 / 2} / \mathrm{ft}^{3 / 4}\right)\end{array}$ & 1439 & 1352 \\
\hline $\begin{array}{l}\text { Suction Specific Speed, } \mathrm{N}_{\mathrm{SS}} \\
\left(\mathrm{rpm}^{\prime} \mathrm{gpm}^{1 / 2} / \mathrm{ft}^{3 / 4}\right)\end{array}$ & \multicolumn{2}{|c|}{8810} \\
\hline$\Delta \mathrm{P}_{\mathrm{t}}$ Impeller Only (psi) & 149.6 & 156.5 \\
\hline$\Delta \mathrm{P}_{\mathrm{t}}$, Vaneless Diffuser (psi) & -5.1 & -15.1 \\
\hline Tot. Head Rise $(\mathrm{ft}(\mathrm{m}))$ & 334.7 & 320.5 \\
\hline NPSP, Impeller (psi) & \multicolumn{2}{|c|}{$\frac{1}{25.7}$} \\
\hline NPSH $(\mathrm{ft}(\mathrm{m}))$ & \multicolumn{2}{|c|}{59.6} \\
\hline Hydraulic efficiency & 0.95 & 0.965 \\
\hline Required Power (hp) & 87.0 & 91.9 \\
\hline
\end{tabular}

Table 1. Pump stage predicted performance parameters.

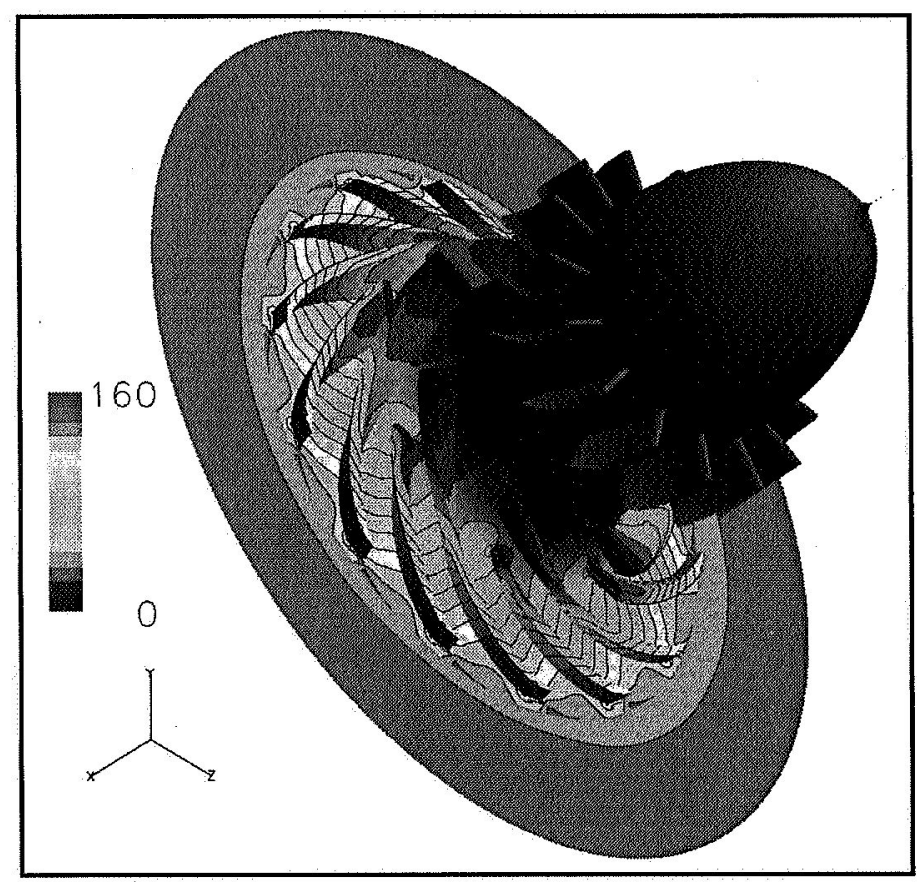

Figure 7. Time-averaged static pressure (psia) on hub and airfoils surfaces; flow enters from upper right.

Figures $8 \mathrm{a}$ and $8 \mathrm{~b}$ illustrate, respectively, the timeaveraged and instantaneous relative total pressure contours at mid-span. The abrupt changes in the contours between the impeller trailing edge and vaneless diffuser are due to the rotation of the impeller grids (i.e., reference frame change). Figures $8 \mathrm{a}$ and $8 \mathrm{~b}$ show the interaction between the IGV wakes and the impeller blades, as well as the frictional losses in the vaneless diffuser section. Additional losses are noted near the leading edges of the impeller splitter blades. The length of the splitter blades was chosen based on a compromise between suppressing separation on the main blades and minimizing frictional losses on the splitter blades.

Figure 9 compares the time-averaged numerical solution with meanline predictions for hydrodynamic efficiency and total head coefficient. The CFD and meanline predictions for the design-flow efficiency are nearly identical (with either a vaneless or vaned diffuser), while the CFD predictions using a vaneless diffuser indicate lower efficiencies at the lower flow rates. The differences in the efficiencies at a flow coefficient of 0.5 are probably the results of several factors, including the use of empirical correlations in the meanline analysis, and

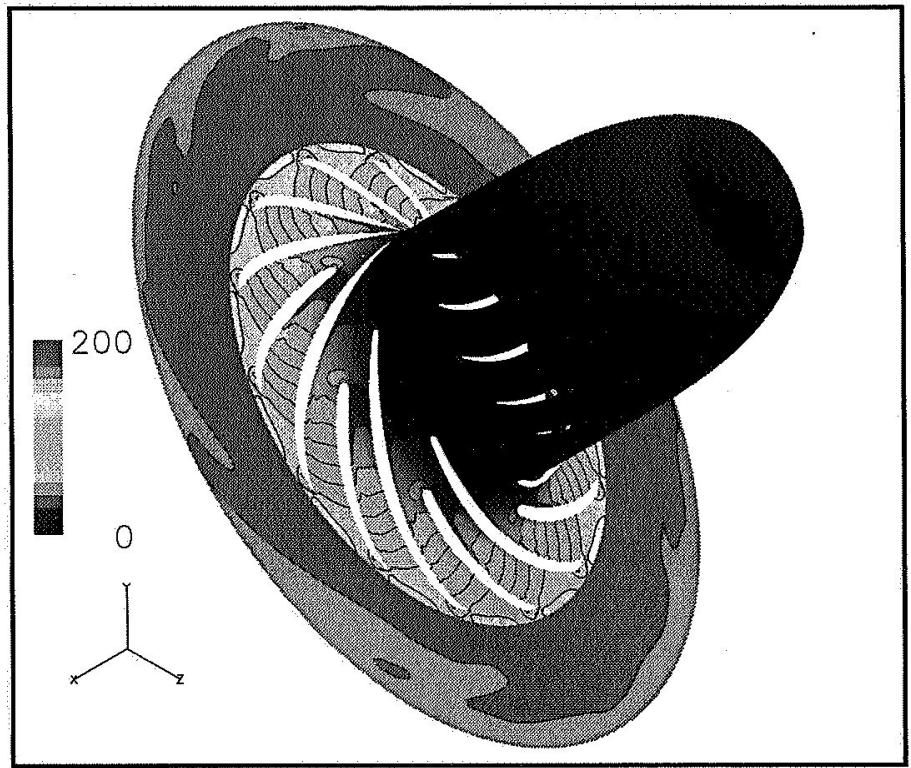

Figure 8a. Time-averaged relative total pressure (psia) at mid-span; flow enters from upper right.

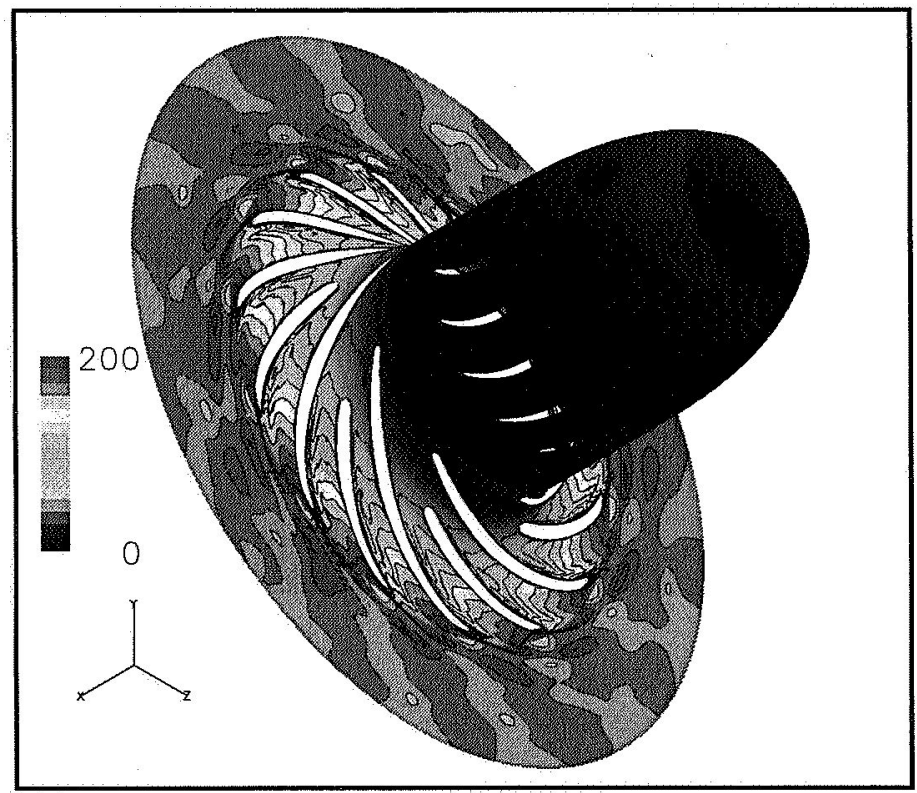

Figure $\mathbf{8 b}$. Instantaneous relative total pressure (psia) at midspan; flow enters from upper right.

inaccuracies in the CFD turbulence model when the flow field contains significant separation. The CFD and meanline predictions for the head coefficient show similar trends, with 
the CFD results being approximately 0.04 lower across the flow range studied (again, with a vaneless diffuser).

Figure 10 illustrates the CFD predictions of incidence and deviation angles for the first-stage impeller. The former reflects a shallow layer of backflow near the shroud, however the upstream extent is minimal. The backflow near the shroud is

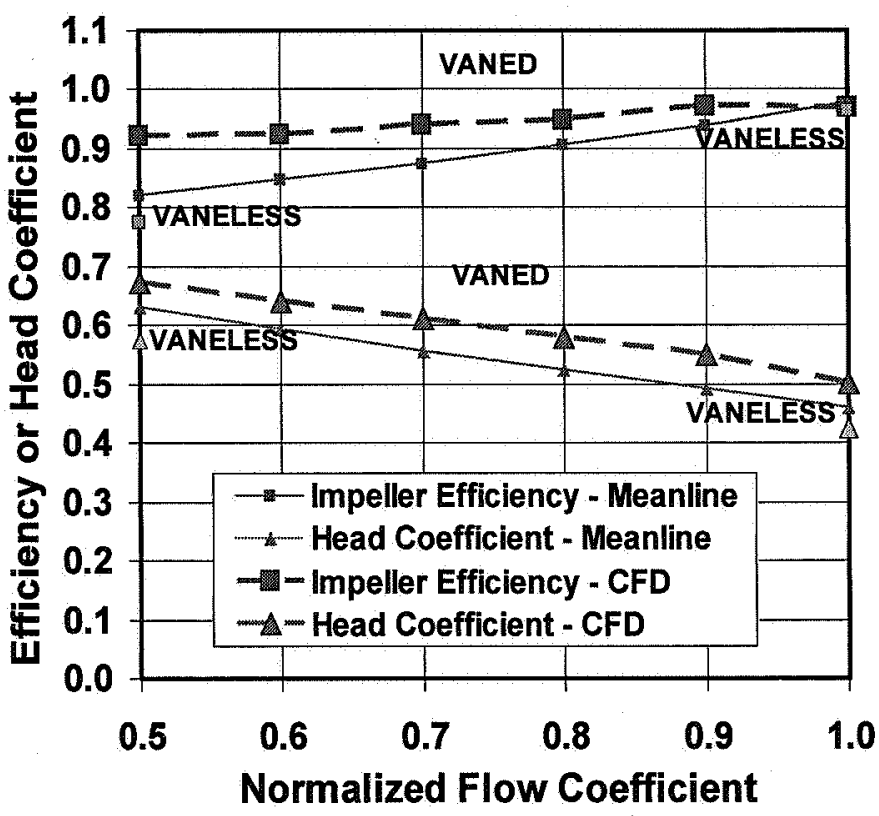

Figure 9. CFD and meanline predictions of hydraulic efficiency and total head coefficient (impeller only) for CFD runs using vaned and vaneless diffusers.

generated by the pressure gradient across the tip clearance near the leading edge of the main impeller blades. Most of the remaining inlet flow has nearly constant flow angle. The impeller exit flow also has nearly constant angle, except for a region of vortical flow (due to the tip leakage vortex) evident near the shroud.

\section{DIFFUSER DESIGN}

In an effort to improve the off-design performance of the pump, as well as to provide structural support to the volute separation loads, vanes were added to the diffuser section. The shape of the diffuser vanes was generated using traditional rules of thumb $[12,13]$ and a pump geometry generator [14]. There were several constraints considered in the design of the diffuser vanes:

1) The pump has 15 inlet guide vanes and 14 impeller blades ( 7 full blades and 7 splitter blades); to avoid amplification of unsteady pressure waves, the number of vanes was chosen to be a prime number greater than 15 (prime numbers less than 15 would have resulted in unacceptable pitch-to-chord ratios).
2) The diffuser has to be large enough to accept $3 / 8$ inch bolts. This requirement is mainly for the water flow. test rig, although a similar requirement would probably exist for the engine.

3) The pump has a collector located downstream of the diffuser, which limits the length of the vanes.

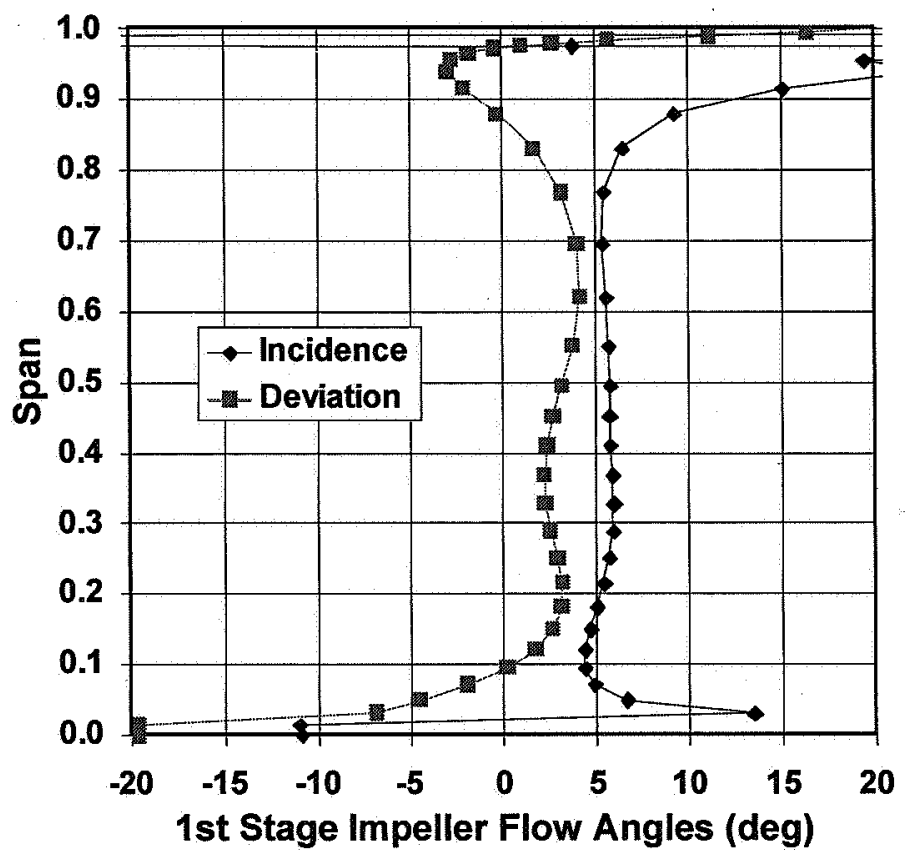

Figure 10. Spanwise profiles of predicted incidence (diamonds) and deviation angle (squares).

The optimum [12] and design values of several design parameters are shown in Table 2. The final diffuser design contains 17 vanes, and is shown in Fig. 11.

\begin{tabular}{|c|c|c|}
\hline Variable & Optimum & Actual \\
\hline $\mathbf{L} / \mathbf{W}_{\mathbf{1}}$ & 4.00 & 2.60 \\
\hline $\mathrm{W}_{\mathbf{2}} / \mathrm{W}_{\mathbf{1}}$ & 1.60 & 1.34 \\
\hline $\boldsymbol{\theta}$ (deg) & 10.0 & 7.40 \\
\hline
\end{tabular}

Table 2. Diffuser design parameters.

Figure 9 contains predicted performance of the pump stage with the diffuser vanes compared to the performance of the same stage with a vaneless diffuser.

The pump stage with the vaned diffuser exhibits similar performance to the stage with the vaneless diffuser at the design flow conditions, but improved performance at the low flow conditions. The improved performance is a result of delayed flow separation along the endwalls of the diffuser passage. As future engines will need to throttle over a wide range of conditions, the diffuser was deemed acceptable as a baseline for future designs. 
Figures 12 and 13 show the time-averaged surface pressures on the impeller and diffuser at $50 \%$ mass flow for water rig test conditions.

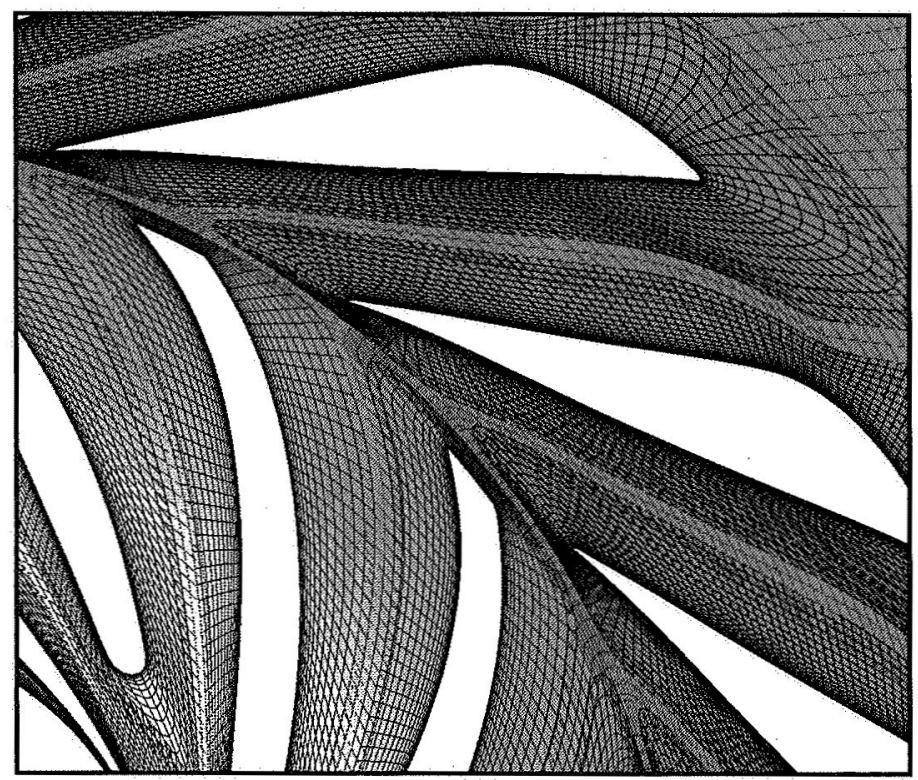

Figure 11. Final diffuser design.

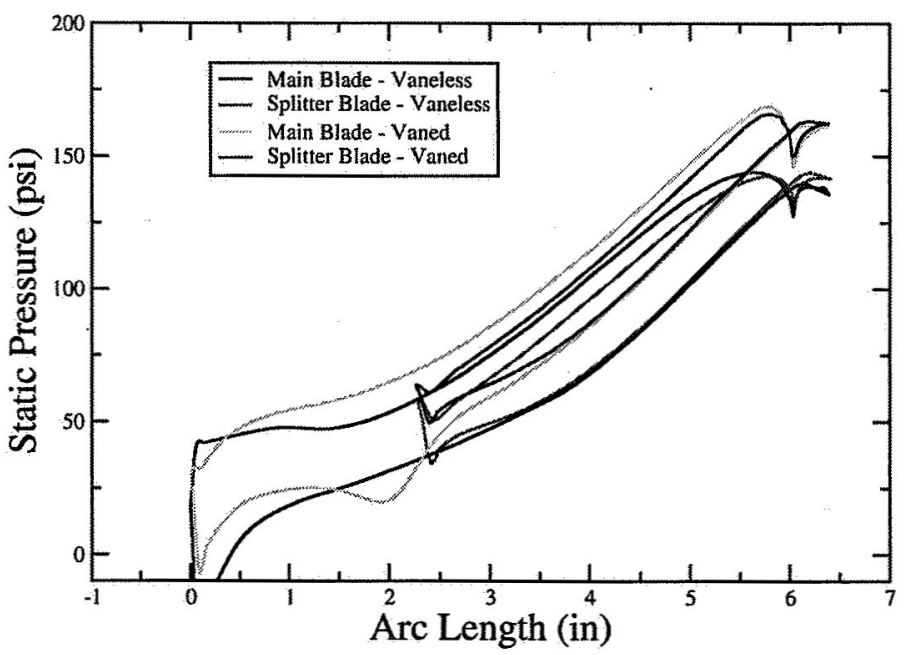

Figure 12. Impeller blade loadings at $50 \%$ flow.

The addition of the vaned diffuser generates greater pressure rise in both the impeller and the diffuser at the low flow conditions. The general characteristics of the impeller loading distributions were the same for all flow conditions.

Figures 14 and 15 contain an unsteady pressure trace and the corresponding Fourier decomposition, respectively, at the trailing edge of an impeller main blade. The predominant unsteadiness experienced by the impeller is at the vane passing frequency, relative to the impeller, of $1020 \mathrm{~Hz}$ and its first harmonic $(2040 \mathrm{~Hz})$. The amplitude of the unsteadiness, approximately $12 \%$ of the mean pressure, is moderate compared to other impeller-diffuser combinations used in rocket turbopump applications. Figures 16 and 17 contain an unsteady pressure trace, and the corresponding Fourier decomposition,

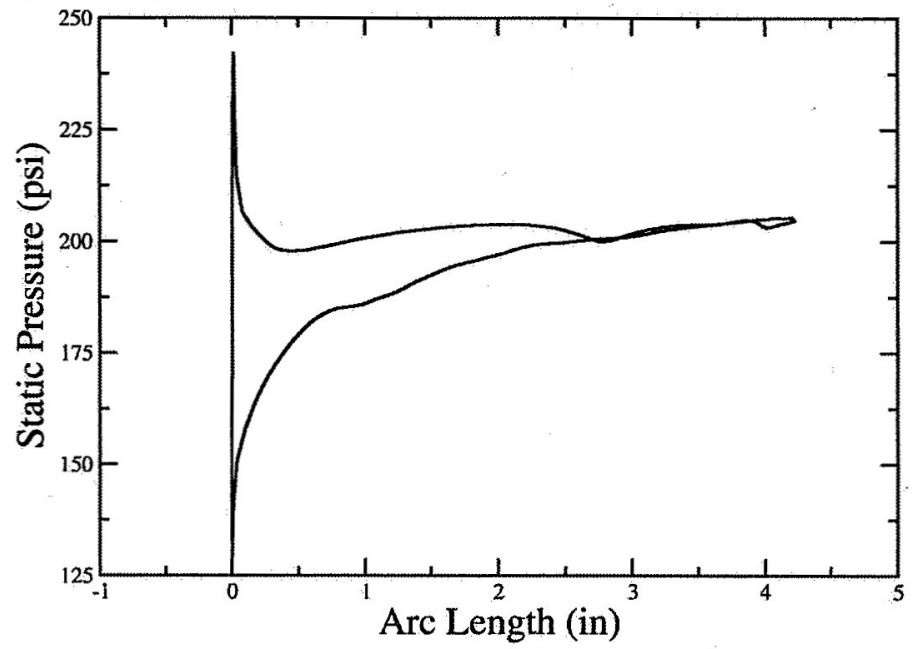

Figure 13. Diffuser vane loading at $50 \%$ flow.

at the leading edge of a diffuser vane. The predominant frequency at the leading edge of the diffuser is the impeller blade passing frequency of $840 \mathrm{~Hz}$, and its first harmonic. There is also lower frequency unsteadiness which is caused by non-periodic boundary layer shedding in the vane passage.

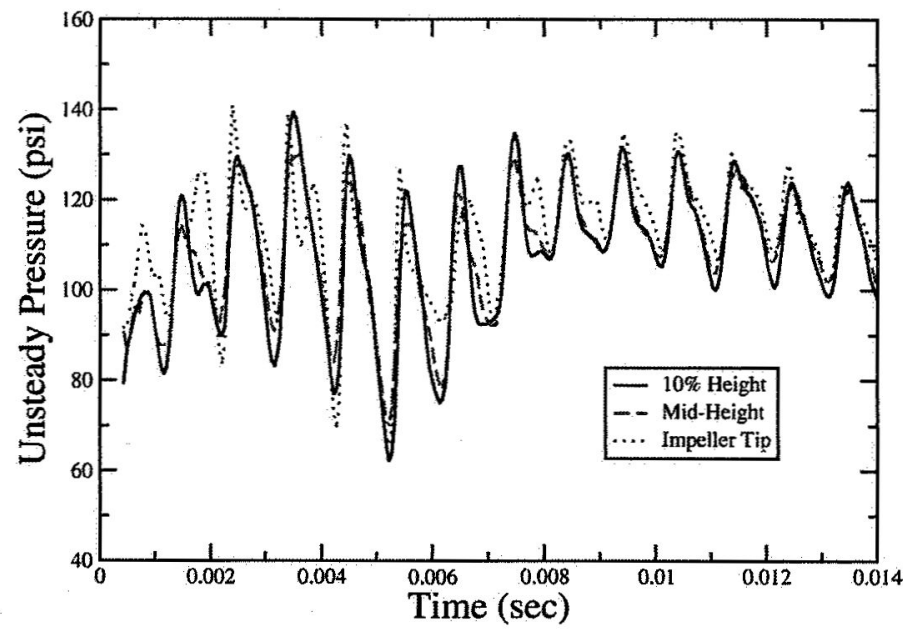

Figure 14. Unsteady pressure trace at the trailing edge of the impeller.

\section{MECHANICAL DESIGN OF WATER FLOW RIG}

A water flow test rig was previously designed, fabricated and tested to support MSFC technology development for unshrouded impellers. To minimize costs for evaluating performance of the new impeller and discharge diffuser 
designs, the reuse of hardware from the previous test rig was maximized. Based on the full-scale impeller and vaneless diffuser geometries, as well as the speed and power capabilities of the drive motor, a scale factor greater than one was selected to provide a good fit with the existing test rig. Design and fabrication of the following hardware was required to support this project:

- impeller, unshrouded

- inlet guide vane

- front shroud

- rear shroud

- labyrinth seal, backface

- diffuser, vaneless

- diffuser, vaned

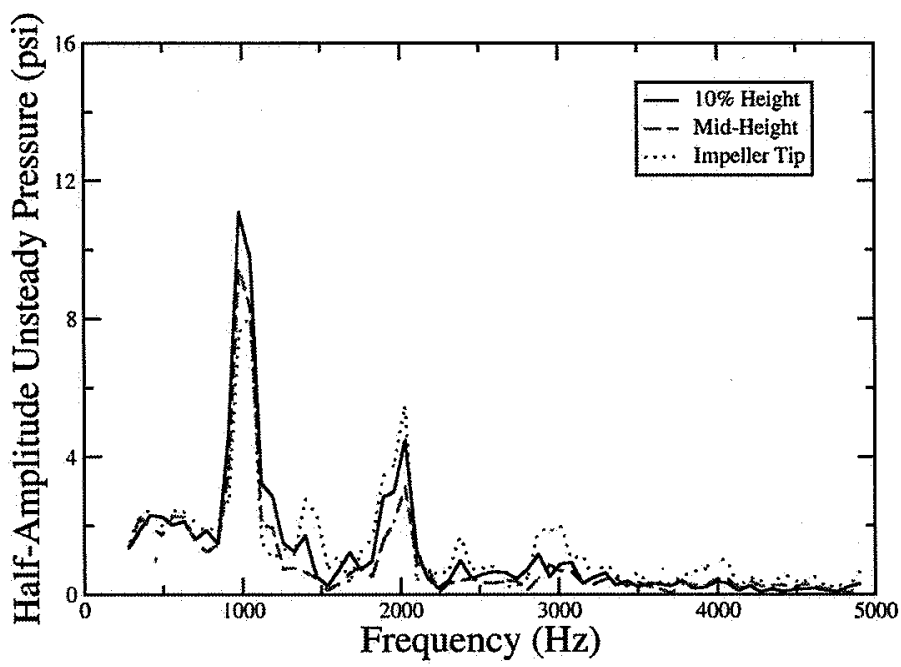

Figure 15. Pressure spectrum at the impeller trailing edge.

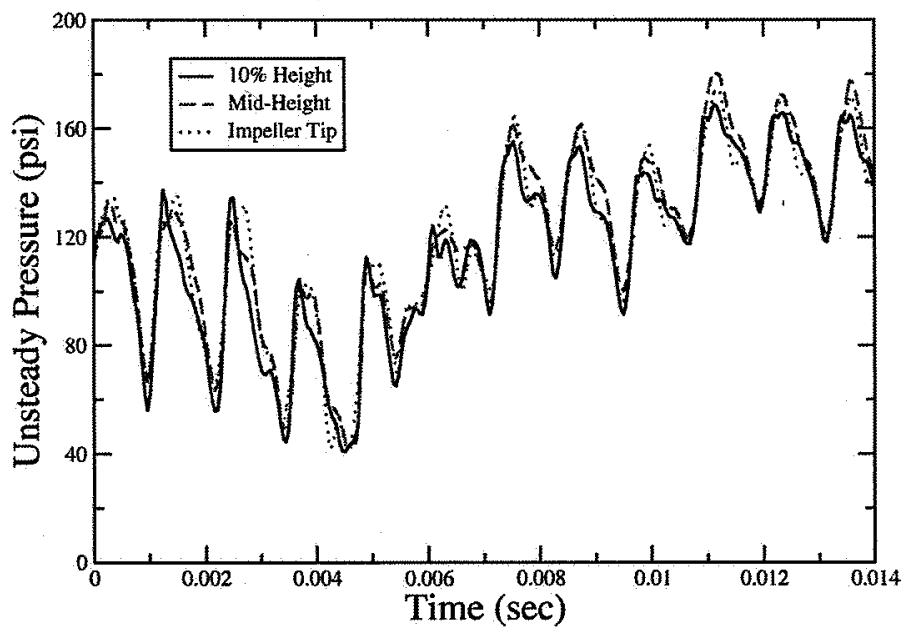

Figure 16. Unsteady pressure at the diffuser leading edge.

Interfacing new hardware with the existing shaft and main housings resulted in a few less than optimum design conditions. The previous test rig utilized 23 discharge diffuser vanes. In addition to the performance benefit they provided, each vane incorporated a stud which supported the pressure separation loads internal to the pump. To provide this function for the vaneless diffuser configuration, 23 struts were required down-

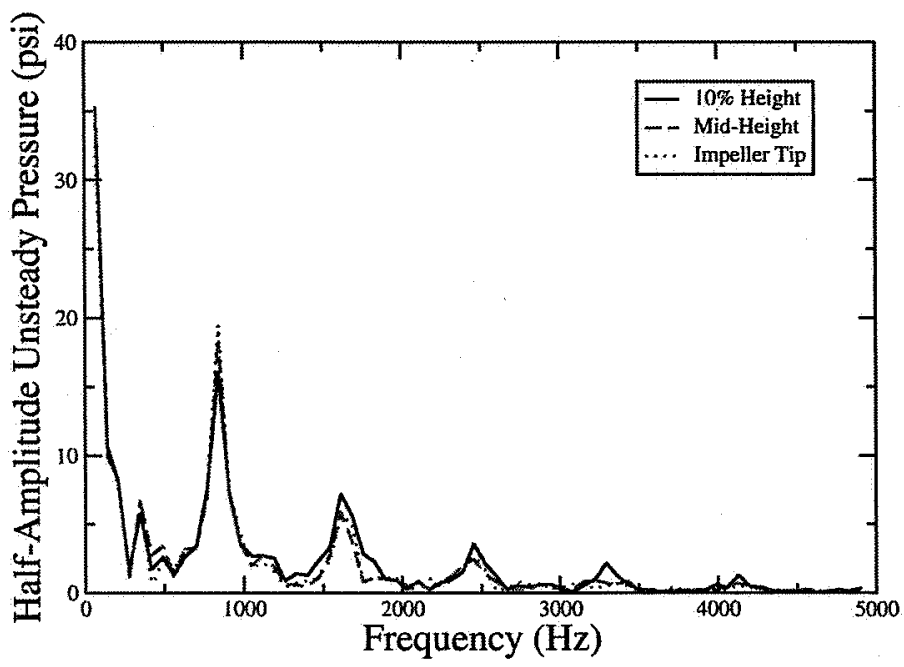

Figure 17. Pressure spectrum at the diffuser leading edge.

stream of the diffuser section so that the studs could be utilized. To minimize flow effects, these contoured struts were designed by CFD. The vaned diffuser configuration presented a similar challenge. The diffuser performance with a 23 vane configuration was not acceptable. Therefore, the same 23 studs could not be used to provide the load path across the vaned diffuser. In addition, incorporating fasteners through the vanes meant they needed to be thicker than optimum. Thus, a configuration with 17 vanes was selected. The studs were replaced with three sets of fasteners: 23 screws to attach a diffuser spacer to the mounting housing, 17 screws to attach the vaned diffuser to the diffuser spacer, and 23 screws to attach the inlet housing to the vaned diffuser. Layout of the test rig instrumentation also dictated that modifications to the existing inlet housing were required.

\section{EXPERIMENTAL TEST}

A wide range of experiments will be performed in the Marshall Space Flight Center Pump Test Equipment (PTE) facility during the spring of 2006. The experimental test will acquire performance data at scaled operating conditions in water for two configurations: impeller with vaneless diffuser and impeller with vaned diffuser. Efficiency, head rise, interstage pressures, dynamic pressures, and inlet and exit flow angles will be measured for each combination of impeller and diffuser in order to assess any differences in performance, dynamic stability, or throttleability. Each configuration will be tested from non-cavitated conditions to complete head breakdown from at least $50 \%$ to as high as $120 \%$ of the reference flow coefficient at a constant speed of $3600 \mathrm{rpm}$. Data will be acquired in one of two modes: (1) dwells with set 
point conditions held constant for data acquisition with low frequency response sensors, and (2) ramps with operating conditions varied continuously during data acquisition with high frequency response devices. The unshrouded impeller tip clearance will be held constant at $5.7 \%$ of the impeller exit blade height.

\section{FACILITY DESCRIPTION}

All tests will be conducted in the PTE facility. The PTE is a closed-loop water flow facility with 10,000-gallon reservoir, de-aeration and pressurization systems, facility flow meter, flow control valve, and 350 horsepower drive motor. The test facility flow schematic is shown in Fig. 18.

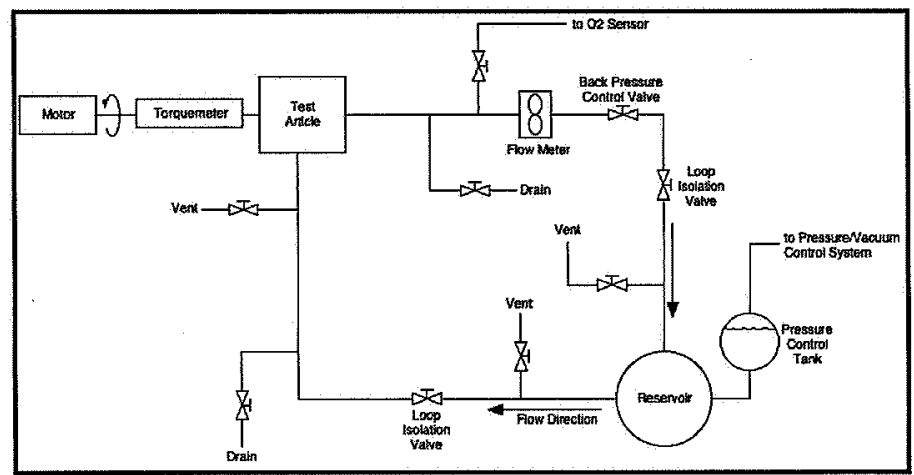

Figure 18. Pump test equipment facility schematic.

In operation flow leaves the reservoir through a 12 -inch line, transitions to an 8-inch line inside the building, and enters the test article's axial inlet. An instrumentation spool just upstream of the test article inlet provides access for total pressure surveys and measurements of the pump inlet total pressure and water temperature. High pressure pump discharge flow exits through an instrumentation spool and passes through an eight inch turbine-type flow meter and back pressure valve on its way back to the reservoir. All piping is stainless steel schedule 40 with the pump discharge pressure limited to 350 psia due to the lower flow meter pressure rating. Isolation valves, drains, and vents are included where required.

Test article inlet pressure is controlled by adjusting the ullage pressure in a partially filled 500-gallon tank mounted on top of and connected to the 10,000-gallon reservoir. The small air and water vapor volume in this pressure control tank may be pressurized with high-purity air, vented to atmosphere, or evacuated with the dual vacuum pumps located in the test facility. These operations, coupled with the line losses between the reservoir and test article inlet, can be used to set any of a wide range of inlet pressures, from 75 psia down to 4 psia. Dissolved air is removed from the test fluid by applying a vacuum to the water-filled test loop and slowly circulating the fluid until the desired dissolved oxygen content is reached.

The PTE driveline includes a 350 horsepower 3-phase AC motor with operation from 360 to $3600 \mathrm{rpm}$ via a variable speed motor controller. A Torquetronics torquemeter is located between the test article and drive motor for true torque measurement. Shear couplings between the test article and torque meter protect the device from pump shaft over-torque. A steam heat exchanger in the reservoir may be used to increase water temperatures up to 150 degrees Fahrenheit. However, cooling the water is not possible except through complete or partial replacement of water in the test loop with cooler fluid.

Shaft speed, facility flow rate, inlet total pressure, water temperature, test article pressure rise, and test article bearing temperatures are monitored at the control panel by the facility operator. The operator has direct control over each of these parameters, except bearing temperature and test article pressure rise, and virtually any combination may be set.

\section{CONCLUSIONS}

The turbopump for an upper stage expander-cycle rocket engine has been designed and analyzed. The use of a radial turbine allows higher pump speeds, resulting in higher pump efficiencies. The pump efficiencies and head rise coefficients predicted for the first stage of the pump using CFD matched well with those obtained from a meanline analysis. Both analyses predict that the pump will meet the design requirements. The first stage of the pump will be tested in water during Summer 2006.

\section{ACKNOWLEDGMENTS}

The authors would like to acknowledge the use of the supercomputer facilities at NASA Ames Research Center, and especially thank Mr. Chuck Niggley for his assistance.

\section{NOMENCLATURE}

$\mathrm{H}$ - static head coefficient

$\mathrm{H}_{\mathrm{t}} \quad$ - total head coefficient

L - length of covered portion of diffuser channel

$\mathrm{W}_{1} \quad$ - width of diffuser channel at inlet

$\mathrm{W}_{2} \quad$ - width of diffuser channel at exit

$\mathrm{y}^{+} \quad$ - friction Reynolds number

$\theta \quad$ - diffuser channel divergence angle

\section{REFERENCES}

[1] Leahy, J. C. and Bates III, L. L., 2003, "Features and Results Using P-STAR: A Propulsion Sizing, Thermal Analysis, and Weight Relationship First Order Modeling Tool," JANNAF CS/APS/MSS/PSHS Meeting, Las Vegas, NV, December.

[2] User's Guides to Pumpal and CCAD, 2000, Concepts NREC, Inc., 217 Billings Farm Road, White River Jct., VT 05001.

[3] Venkateswaran, S. and Merkle, C. L., 1999, "Analysis of Preconditioning Methods for the Euler and Navier-Stokes Equations," Von Karman Institute Lecture Series, March 8-12.

[4] Dorney, D. J., and Schwab, J. R., 1996, "Unsteady Numerical Simulations of Radial Temperature Profile 
Redistribution in a Single-Stage Turbine," ASME Journal of Turbomachinery, 118 (4), pp. 783-791.

[5] Roe, P. L., "Approximate Riemann Solvers, Parameter Vectors, and Difference Schemes," 1981, Journal of Computational Physics, 43, pp. 357-372.

[6] Baldwin, B. S., and Lomax, H., 1978, "Thin Layer Approximation and Algebraic Model for Separated Turbulent Flow," AIAA Paper 78-257, Huntsville, AL, January.

[7] Oefelein, J. C., 2002, Sandia Corporation, Livermore, CA, Private Communication, December.

[8] http://webbook.nist.gov/chemistry/fluid

[9] Sondak, D. L. and Dorney, D. J., 2003, "General Equation Set Solver for Compressible and Incompressible Turbomachinery Flows," AIAA 2003-4420, 39th AIAA/ASME/SAE/ASEE Joint Propulsion Conference and Exhibit, Huntsville, AL, July 20-23.

[10] Merkle, C. L., Venkateswaran, S., Dorney, D. J., and Sondak, D. L., 2003, "A Generalized Fluid Formulation for Turbomachinery Computations," AIAA 2003-3999, 33rd AIAA Fluid Dynamics Conference and Exhibit, Orlando, FL, June 23-26.

[11] Dorney, D. J., Sondak, D. L. and Marcu, B., 2005, "Application of a Real-Fluid Turbomachinery Analysis to Rocket Turbopump Geometries," AIAA 2005-1007, 43rd AIAA Aerospace Sciences Meeting and Exhibit, Reno, NV, January 10-13.

[12] Stepanoff, A. J., 1993, Centrifugal and Axial Flow Pumps, 2nd Edition, Krieger Publishing Company, Malabar, FL.

[13] Japikse, D., Marscher, W. D., and Furst, R. B., 1997, Centrifugal Pump Design and Performance, Concepts ETI, Inc., Wilder, VT.

[14] Huber, F. W., 2005, "Improvements in Turbomachinery Meanline Design and Analysis Tools," Quarterly Report 2, NASA Contract NNM05AG89P. 